EVIDENCE BASED PUBLIC HEALTH POLICY AND PRACTICE

\title{
Relation between increased numbers of safe playing areas and decreased vehicle related child mortality rates in Japan from 1970 to 1985: a trend analysis
}

\author{
Shinii Nakahara, Yasuhide Nakamura, Masao Ichikawa, Susumu Wakai
}

J Epidemiol Community Health 2004;58:976-981. doi: 10.1136/jech.2003.018804

\begin{abstract}
See end of article for authors' affiliations

.....................

Correspondence to: Dr S Nakahara, Department of International Community Health, Graduate School of Medicine, The University of Tokyo, 7-3-1 Hongo, Bunkyo-ku, Tokyo 113 0033, Japan; shinji@ m.u-tokyo.ac.jp
\end{abstract}

Accepted for publication 26 April 2004

\begin{abstract}
Objectives: To examine vehicle related mortality trends of children in Japan; and to investigate how environmental modifications such as the installation of public parks and pavements are associated with these trends.

Design: Poisson regression was used for trend analysis, and multiple regression modelling was used to investigate the associations between trends in environmental modifications and trends in motor vehicle related child mortality rates.

Setting: Mortality data of Japan from 1970 to 1994, defined as E-code 810-23 from 1970 to 1978 and E810-25 from 1979 to 1994, were obtained from vital statistics. Multiple regression modelling was confined to the 1970-1985 data. Data concerning public parks and other facilities were obtained from the Ministry of Land, Infrastructure, and Transport.

Subjects: Children aged 0-1 4 years old were examined in this study and divided into two groups: 0-4 and 5-14 years.

Main results: An increased number of public parks was associated with decreased vehicle related mortality rates among children aged $0-4$ years, but not among children aged 5-14. In contrast, there was no association between trends in pavements and mortality rates.

Conclusions: An increased number of public parks might reduce vehicle related preschooler deaths, in particular those involving pedestrians. Safe play areas in residential areas might reduce the risk of vehicle related child death by lessening the journey both to and from such areas as well as reducing the number of children playing on the street. However, such measures might not be effective in reducing the vehicle related mortalities of school age children who have an expanded range of activities and walk longer distances.
\end{abstract}

$\mathrm{R}$ oad traffic injuries are a leading cause of child morbidity and mortality in Japan. Every year, more than 86000 children under the age of 15 years are injured, ${ }^{1}$ and more than 350 are killed in motor vehicle crashes. ${ }^{2}$ Child traffic deaths rapidly increased during the 1950s and 1960s, and reached a peak in $1970^{13}$; injuries to pedestrians accounted for most of these deaths. ${ }^{12}$ Enacting the Traffic Safety Policy Law in 1970, the Japanese government reinforced countermeasures focusing particularly on child pedestrians. ${ }^{4}$ Consequently, the pedestrian mortality rate of children under the age of 15 years gradually declined to a similar rate seen in other industrialised countries. ${ }^{15-7}$ However, the pedestrian mortality rates of adults only showed a decline in the early 1970s, after which no significant improvements have been observed. ${ }^{5}$

A possible explanation for this decreased child pedestrian mortality rate is the reduction in children partaking in outdoor activities. ${ }^{8}$ The effects of countermeasures specifically targeted at children should, however, also be considered. ${ }^{5}$ These countermeasures include: an increased number of public parks and the opening of school grounds to the public to reduce playing in the street; the intensive instalment and implementation of safety facilities and traffic regulations near schools; and school education programmes on road safety. Studies show that among these measures, modifications in living environments seem to have significantly contributed to the reduction in child pedestrian mortality rates. ${ }^{9} 10$

Few studies, however, have evaluated the effectiveness of these environmental modifications. Studies in the US showed no relation between the presence of local neighbourhood play areas and a reduced risk of pedestrian injuries among children under the age of 15 years, ${ }^{11}{ }^{12}$ although adjacent play areas, front or back yard play areas that do not require crossing roads, did present a lowered risk. ${ }^{12}$ Furthermore, the presence of pavements was not associated with a lowered risk. ${ }^{12}{ }^{13}$ A German study, however, showed that a high density of neighbourhood play parks slightly reduced the risk of school age pedestrian injuries. ${ }^{14}$ These studies, however, did not focus on preschool children who are more likely to benefit from these neighbourhood play areas as they are more likely to be injured when playing near the home. ${ }^{15}$ Therefore, this study examined trends in motor vehicle related child mortality rates in Japan, and investigated the relations between trends in child motor vehicle related mortality rates and trends in safe play areas and other safety facilities. Prefectural data from 1970 to1985 were used and special attention was paid to the differences in that of preschool and school age children.

\section{METHODS}

\section{Study setting}

Japan is divided into 47 prefectures, the largest local administration unit, with populations ranging from 613289 to $12064 \mathrm{101}$, and the size of inhabitable areas ranging from $1875.88 \mathrm{~km}^{2}$ to $83453.04 \mathrm{~km}^{2} .{ }^{16}$ In 1972, Okinawa prefecture

Abbreviations: MOHWL, Ministry of Health, Welfare and Labour; MPHPT, Ministry of Public Mangement, Home Affairs, Posts and Telecommunications; EMS, emergency medical services; DDI, densely inhabited districts 
Table 1 Traffic safety measures and environments in Japan from 1970 to 1995

\begin{tabular}{|c|c|c|c|c|c|c|}
\hline & $1970^{*}$ & 1975 & 1980 & 1985 & 1990 & 1995 \\
\hline \multicolumn{7}{|l|}{ Safety facilities } \\
\hline Proportion of local roads with pavements (\%) & 0.7 & 1.4 & 2.6 & 3.7 & 5.2 & 6.2 \\
\hline Proportion of main roads with pavements (\%) & 7.1 & 13.1 & 19.6 & 25.9 & 31.8 & 36.0 \\
\hline $\begin{array}{l}\text { Number of pedestrian crossing per road } \\
\text { length }(/ 1000 \mathrm{~km})\end{array}$ & 132.3 & 321.6 & 516.3 & 640.2 & 722.0 & 773.3 \\
\hline $\begin{array}{l}\text { Number of traffic signals per road length } \\
(/ 1000 \mathrm{~km}) \dagger\end{array}$ & - & 59.9 & 91.0 & 106.3 & 122.2 & 138.8 \\
\hline \multicolumn{7}{|l|}{ Living environments } \\
\hline $\begin{array}{l}\text { Number of public parks per habitable area } \\
\left(/ 100 \mathrm{~km}^{2}\right)\end{array}$ & 11.3 & 17.5 & 27.9 & 38.3 & 46.3 & 53.9 \\
\hline $\begin{array}{l}\text { Traffic volume (100,000 vehicle } \mathrm{km} / 12 \mathrm{~h}) \\
\text { Lifestyle }\end{array}$ & 4350.0 & 4959.4 & 6074.7 & 6784.6 & 8040.1 & 8806.1 \\
\hline $\begin{array}{l}\text { Proportion of children attending preschool (\%) } \\
\text { Law enforcements }\end{array}$ & 78.2 & 89.4 & 89.0 & 91.1 & 94.8 & 94.3 \\
\hline $\begin{array}{l}\text { Number of infringement notices of traffic } \\
\text { violation/traffic volume }(/ 100000 \text { vehicle } \\
\mathrm{km} / 12 \mathrm{~h}) \\
\text { Urbanisation }\end{array}$ & 1213.6 & 2048.4 & 1916.5 & 2016.9 & 1124.4 & 949.7 \\
\hline $\begin{array}{l}\text { Proportion of population living in densely } \\
\text { inhabited districts (\%) }\end{array}$ & 53.5 & 57.0 & 59.7 & 60.6 & 63.2 & 64.7 \\
\hline \multicolumn{7}{|l|}{ Emergency medical service } \\
\hline $\begin{array}{l}\text { Number of ambulances per habitable area } \\
\left(/ 100 \mathrm{~km}^{2}\right)\end{array}$ & 1.1 & 2.4 & 3.3 & 3.6 & 3.8 & 4.1 \\
\hline
\end{tabular}

was returned to Japan from the United States and therefore its data before this are not available.

We examined trends in motor vehicle related, pedestrian, cyclist, and occupant mortalities among children aged 0-4 and 5-14 years for the period 1970-94. Using prefectural data, we then examined the relation between trends in environmental modifications and trends in motor vehicle related mortality rates among children within these two age brackets from 1970-85.

\section{Data on mortality rates}

Mortality data were obtained from the vital statistics compiled by the Ministry of Health, Welfare and Labour (MOHWL), Japan. In this study, motor vehicle related deaths were defined as E code 810-823 for 1970-78 according to the eighth revision of the International Classification of Diseases (ICD-8), and E810-825 for 1979-94 according to ICD-9. Pedestrian deaths were defined as E814 and E820 for 197078 (ICD-8), and E810-825.7 for 1979-94 (ICD-9). Because
E810-823.7 data were not available for 1970-78, E814 and E820 were used as a proxy, because they are almost identical to E810-819.7 and E820-825.7, respectively, for 1979-94. Likewise, cyclist deaths were defined as E813 in 1970-78 and E810-825.6 for 1979-94. All other motor vehicle related deaths were defined as occupant deaths, and included few undetermined deaths.

Changes between the eighth and ninth revision involved the addition of only two codes: E820 (non-traffic accident involving motor driven snow vehicles) and E821 (non-traffic accident involving off road motor vehicles). This change had no substantial influence on analysis because within the study period only three and 16 child deaths fell into these categories, respectively.

Population data were obtained from the national censuses conducted in 1970, 1975, 1980, 1985, and 1990; and for other years, from population estimations compiled by the Ministry of Public Management, Home Affairs, Posts and Telecommunications (MPHPT).

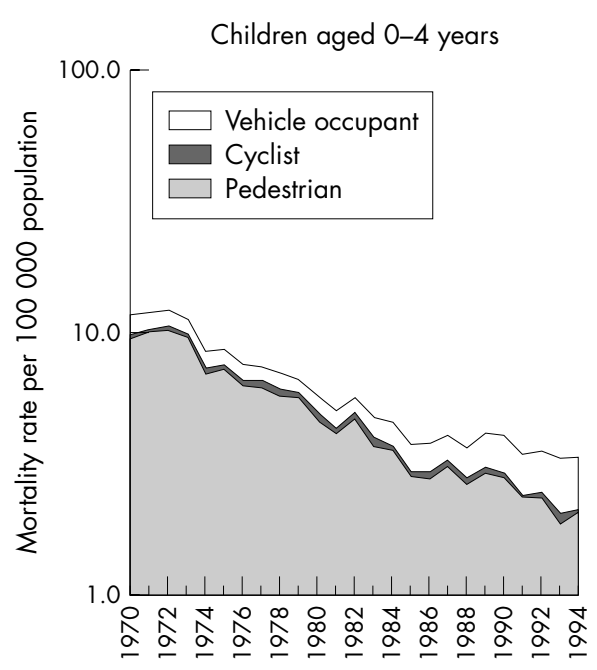

Year

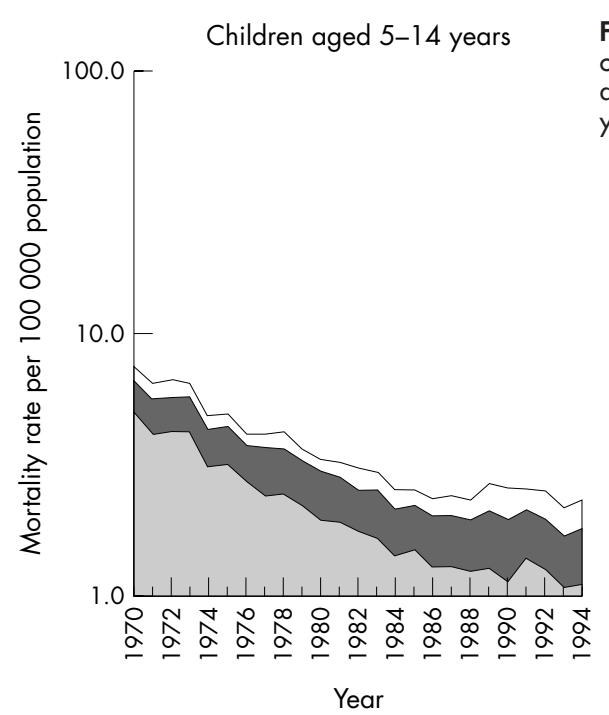

Figure 1 Mortality trends in vehicle occupants, cyclists, and pedestrians among children aged $0-4$ and 5-14 years in Japan from 1970 to 1994. 
Table 2 Annual changes in motor vehicle related mortality* rates and pedestrian mortality† rates

\begin{tabular}{|c|c|c|}
\hline & $\begin{array}{l}\text { Annual \% } \\
\text { change }\end{array}$ & $(95 \% \mathrm{Cl})$ \\
\hline \multicolumn{3}{|l|}{$1970-1985$} \\
\hline Vehicle related mortality rates of children aged $0-4$ years & -7.4 & $(-7.7$ to -6.8$)$ \\
\hline Pedestrian mortality rates of children aged $0-4$ years & -7.8 & $(-8.6$ to -7.7$)$ \\
\hline Vehicle related mortality rates of children aged $5-14$ years & -7.1 & $(-7.7$ to -6.8$)$ \\
\hline $\begin{array}{l}\text { Pedestrian mortality rates of children aged 5-14 years } \\
1986-1994\end{array}$ & -8.2 & $(-8.6$ to -7.7$)$ \\
\hline Vehicle related mortality rates of children aged $0-4$ years & -2.1 & $(-3.9$ to -0.6$)$ \\
\hline Pedestrian mortality rates of children aged $0-4$ years & -4.8 & $(-6.8$ to -3.0$)$ \\
\hline Vehicle related mortality rates of children aged $5-14$ years & -0.2 & $(-2.0$ to 1.0$)$ \\
\hline Pedestrian mortality rates of children aged 5-14 years & -1.6 & $(-3.0$ to 0.2$)$ \\
\hline
\end{tabular}

\section{Rationale for proxy measurements}

Prefectural data regarding pedestrian deaths were not available, but based on our trend analysis (fig 1 and table 2) vehicle related mortality trends can be considered representative of trends in pedestrian mortality rates. The reasoning for this are as follows: (1) vehicle related child deaths consist mainly of pedestrian deaths ${ }^{126} ;(2)$ the decline in pedestrian deaths accounts for a large percentage of the overall decline in vehicle related deaths because cyclists, occupants, and other vehicle related mortality rates did not change over time; (3) the slope of decline in pedestrian mortality rates was similar to that of overall vehicle related mortality rates between 1970 and 1985. Regression modelling was confined to $1970-85$ because between 1986 to 1994 trends in vehicle related and pedestrian mortality rates did not assure the aforementioned assumption.

\section{Independent variables}

As children are usually injured in residential areas, we considered public parks, pavements on local roads, and pedestrian crossings key determinants of child pedestrian mortality. Pavements on main roads were also evaluated. Municipalities maintain the local roads but prefectural or national governments maintain the main roads. The number of infringement notices issued for violations of traffic regulations per traffic volume (100 000 vehicle kilometres travelled) was included as an indicator of law enforcement activities and the number of ambulances per inhabitable area was used as an indicator of emergency medical services (EMS). A simulation study showed that an increased number

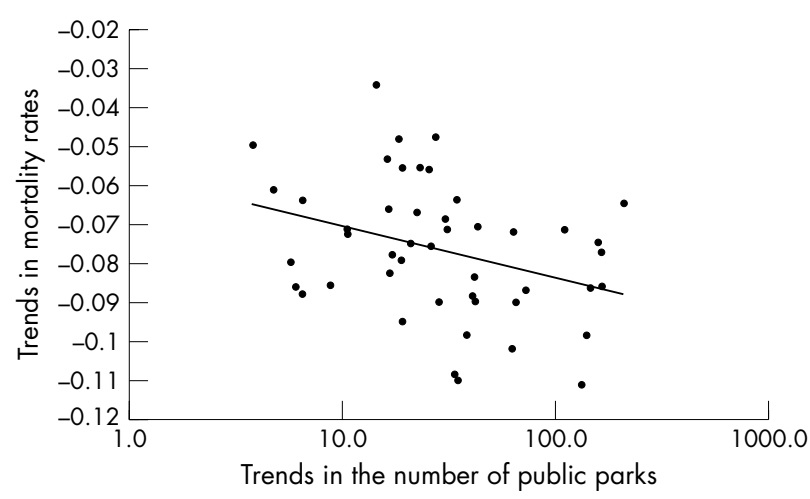

Figure 2 Trends in vehicle related mortality rates among children aged $0-4$ years and trends in public parks in each prefecture from 1970 to 1985. of ambulances would reduce the probability of dispatch delay in areas with no other supplemental EMS networking. ${ }^{17}$ The percentage of children attending preschools was used as an indicator of changes in exposure to risks; children are not exposed to traffic while in preschool facilities. As an indicator of urbanisation, we included the percentage of populations living in densely inhabited districts (DIDs) that are defined as areas with a population density of more than $4000 / \mathrm{km}^{2}$ and a total population of more than 5000. ${ }^{16}$

Data concerning public parks, pavements, and traffic volume (vehicle kilometres travelled) were obtained from the Ministry of Land, Infrastructure, and Transport (MLIT). All other data were obtained from the MPHPT. When data were not available, data of the nearest year were used: pavement data for 1971 were used for 1970; preschool data for 1969 were used for 1970; and traffic volume data for 1971 and 1974 were used for 1970 and 1975, respectively. The number of traffic signals was not included in the regression modelling because data were not available for 1970 .

\section{Analysis}

Mortality trends at national and prefectural levels were obtained using Poisson regression analysis with the following model: $\log m=a_{1}+b_{1} t$ where $m$ equals mortality rate, log is the natural $\log , t$ is the year, and $b_{1}$ is the trend. Annual percentage changes were calculated using the following formula: annual percentage change $=100 \times\left[\exp \left(b_{1}\right)-1\right]$.

Trends of the independent variables at a prefectural level were calculated by simple linear regression of data from 1970, 1975, 1980, and 1985: regression coefficients were defined as trends. Infringement notices increased during the 1970s but decreased in the 1980s, and therefore only the increasing trends from 1970 to 1980 were used assuming the rapid increases in law enforcement during the 1970s influenced subsequent mortality trends. Trends in public parks, pavements, traffic volume, and pedestrian crossings, showed nonlinear relations with mortality trends because of their skewed distributions, and therefore they were log transformed to linearise these associations. ${ }^{18}$

We assessed relations between trends in mortality rates and trends in environmental factors at the prefectural level, using simple linear regression analysis. To determine independent relations, multiple regression models were used. To adjust for traffic environments other than safety facilities, these models included trends in DID area populations, children attending preschool, infringement notices, and traffic volume. Because of multicolinearity, it was not possible to analyse two or more safety facility trends simultaneously, with these models, therefore each safety facility trend was examined independently. 
Table 3 Factors associated with traffic mortality trends, 1970-1985

\begin{tabular}{|c|c|c|c|c|}
\hline Explanatory variables & Coefficient (B) & $(95 \% \mathrm{Cl})$ & Standardised coefficient $(\beta)$ & $r^{2}$ \\
\hline \multicolumn{5}{|l|}{ Children aged $0-4$ years } \\
\hline Public parks* & -0.0057 & $(-0.0104$ to -0.0010$)$ & -0.340 & 0.10 \\
\hline Pavements on local roads* & -0.0062 & $(-0.0139$ to 0.0014$)$ & -0.237 & 0.04 \\
\hline Pavements on main roads* & 0.0043 & $(-0.0116$ to 0.0203$)$ & 0.081 & 0.00 \\
\hline Pedestrian crossings ${ }^{*}$ & -0.0094 & $(-0.0191$ to 0.0002$)$ & -0.281 & 0.08 \\
\hline Infringement notices (1970-1980) & -0.00004 & $(-0.00013$ to 0.00004$)$ & -0.154 & 0.00 \\
\hline Traffic volume* & -0.0035 & $(-0.0140$ to 0.0070$)$ & -0.099 & 0.00 \\
\hline Preschool education & 0.0083 & $(-0.0008$ to 0.0174$)$ & 0.264 & 0.05 \\
\hline Ambulance & -0.0009 & $(-0.0031$ to 0.0013$)$ & -0.123 & 0.00 \\
\hline DID population & 0.0073 & $(-0.0129$ to 0.0274$)$ & 0.107 & 0.00 \\
\hline \multicolumn{5}{|l|}{ Children aged $5-14$ years } \\
\hline Public parks* & -0.0046 & $(-0.0109$ to 0.0017$)$ & -0.216 & 0.03 \\
\hline Pavements on local roads* & -0.0082 & $(-0.0180$ to 0.0016$)$ & -0.244 & 0.04 \\
\hline Pavements on main roads* & -0.0163 & $(-0.0361$ to 0.0036$)$ & -0.238 & 0.04 \\
\hline Pedestrian crossings ${ }^{*}$ & -0.0144 & $(-0.0265$ to -0.0023$)$ & -0.336 & 0.09 \\
\hline Infringement notices (1970-1980) & -0.0001 & $(-0.0002$ to 0.00003$)$ & -0.213 & 0.02 \\
\hline Traffic volume* & -0.0048 & $(-0.0183$ to 0.0086$)$ & -0.108 & 0.00 \\
\hline Preschool education & 0.0028 & $(-0.0093$ to 0.0148$)$ & 0.069 & 0.00 \\
\hline Ambulance & -0.0012 & $(-0.0040$ to 0.0016$)$ & -0.126 & 0.00 \\
\hline DID population & -0.0146 & $(-0.0402$ to 0.0110$)$ & -0.169 & 0.01 \\
\hline
\end{tabular}

\section{RESULTS}

Pavements increased steadily during the study period (table 1), and annual percentage point increases of local and main roads with pavements were 0.23 and 1.2, respectively; however, the proportions of pavement installation alongside local roads were extremely low. The annual increase in pedestrian crossings was 25.9 per $1000 \mathrm{~km}$ of roads. The annual increase in public parks was 1.8 per $100 \mathrm{~km}^{2}$ of habitable area. Other countermeasures and environmental factors, apart from the issue of infringement notices, increased; infringement notices increased during the 1970s but decreased during the late 1980s and 1990s.

Pedestrian mortality accounted for $81.7 \%, 75.7 \%$, and $61.6 \%$ of motor vehicle related mortality in 1970, 1985, and 1994, respectively, among children aged 0-4 years, and $67.8 \%, 58.9 \%$, and $47.3 \%$ in 1970,1985 , and 1994 , respectively, among children aged 5-14 years (fig 1). Motor vehicle related mortality and pedestrian mortality rates among both age groups showed similar and considerable declines until 1985 (7\%-8\% annual reductions) (table 2). But the pace of the reduction slowed down and the variation in the trends increased after 1985. Other categories of vehicle related mortality rates, including cyclists or occupants, did not decline during the study period.

An increased number of public parks were associated with declining mortality among children aged $0-4$ years. In simple regression analyses, the increased number of public parks, pavements on local roads, and pedestrian crossings explained $10 \%, 4 \%$, and $8 \%$ of the mortality changes among children aged 0-4 years, respectively (fig 2, table 3). All were associated with a decline in mortality rates, but only the increased number of public parks showed statistical significance. Among children aged 5-14 years, the increased number of public parks, pavements on local roads, and pedestrian crossings explained 3\%, $4 \%$, and $9 \%$ of mortality rate changes, respectively. The increased number of pedestrian crossings showed a statistically significant correlation with declining mortality.

In multiple regression analysis (table 4), after adjusting for law enforcement activities, traffic volume, preschool attendance, and urbanisation, an increased number of public parks remained the most significant factor related to

Table 4 Results of multiple regression between trends in vehicle related mortality and trends in independent variables, 19701985

\begin{tabular}{|c|c|c|c|c|c|c|c|c|}
\hline \multirow[b]{2}{*}{ Explanatory variables } & \multicolumn{4}{|c|}{ Children aged $0-4$ years } & \multicolumn{4}{|c|}{ Children aged 5-14 years } \\
\hline & $\begin{array}{l}\text { Coefficient } \\
\text { (B) }\end{array}$ & $(95 \%$ C I) & $\begin{array}{l}\text { Standardised } \\
\text { coefficient }(\beta)\end{array}$ & $r^{2}$ & $\begin{array}{l}\text { Coefficient } \\
\text { (B) }\end{array}$ & $(95 \%$ C I) & $\begin{array}{l}\text { Standardised } \\
\text { coefficient }(\beta)\end{array}$ & $r^{2}$ \\
\hline \multicolumn{9}{|l|}{ Model 1} \\
\hline Public park* & -0.0076 & $(-0.0139$ to -0.0013$)$ & -0.454 & 0.20 & -0.0022 & $(-0.0113$ to 0.0069$)$ & -0.103 & 0.00 \\
\hline Infringement notices (1970-1980) & -0.00001 & $(-0.0001$ to 0.0001$)$ & -0.030 & & -0.00006 & $(-0.0002$ to 0.0001$)$ & -0.155 & \\
\hline Traffic volume* & -0.0032 & $(-0.0164$ to 0.0100$)$ & -0.091 & & -0.0031 & $(-0.0222$ to 0.0160$)$ & -0.069 & \\
\hline Preschool education & 0.0111 & $(0.0015$ to 0.0206$)$ & 0.352 & & 0.0060 & $(-0.0077$ to 0.0198$)$ & 0.151 & \\
\hline $\begin{array}{l}\text { DID population } \\
\text { Model } 2\end{array}$ & 0.0177 & $(-0.0023$ to 0.0377$)$ & 0.261 & & -0.0089 & $(-0.0378$ to 0.0200$)$ & -0.103 & \\
\hline Pavements on local roads* & -0.0078 & $(-0.0160$ to 0.0004$)$ & -0.298 & 0.16 & -0.0062 & $(-0.0177$ to 0.0052$)$ & -0.186 & 0.00 \\
\hline Infringement notices (1970-1980) & -0.00002 & $(-0.0001$ to 0.0001$)$ & -0.067 & & -0.00004 & $(-0.0002$ to 0.0001$)$ & -0.119 & \\
\hline Traffic volume* & -0.0114 & $(-0.0229$ to -0.00001$)$ & -0.325 & & -0.0053 & $(-0.0212$ to 0.0106$)$ & -0.118 & \\
\hline Preschool education & 0.0137 & (0.0039 to 0.0235$)$ & 0.436 & & 0.0075 & $(-0.0062$ to 0.0211$)$ & 0.186 & \\
\hline DID population & 0.0155 & $(-0.0048$ to 0.0358$)$ & 0.229 & & -0.0080 & $(-0.0362$ to 0.0203$)$ & -0.092 & \\
\hline \multicolumn{9}{|l|}{ Model 3} \\
\hline Pedestrian crossings* & -0.0086 & $(-0.0195$ to 0.0022$)$ & -0.257 & 0.14 & -0.0130 & $(-0.0275$ to 0.0016$)$ & -0.302 & 0.05 \\
\hline Infringement notices (1970-1980) & -0.00002 & $(-0.0001$ to 0.0001$)$ & -0.061 & & -0.00002 & $(-0.0001$ to 0.0001$)$ & -0.048 & \\
\hline Traffic volume* & -0.0128 & $(-0.0244$ to -0.0011$)$ & -0.363 & & -0.0071 & $(-0.0227$ to 0.0086$)$ & -0.157 & \\
\hline Preschool education & 0.0111 & $(0.0012$ to 0.0211$)$ & 0.354 & & 0.0045 & $(-0.0089$ to .0179$)$ & 0.112 & \\
\hline DID population & 0.0140 & $(-0.0063$ to 0.0344$)$ & 0.208 & & -0.0080 & $(-0.0354$ to 0.0194$)$ & -0.092 & \\
\hline
\end{tabular}


decreased mortality rates of children aged $0-4$ years. This model explained $20 \%$ of the mortality rate changes. Models including pavements or pedestrian crossings, although they did not show significant associations, explained $16 \%$ or $14 \%$ of mortality rate changes, respectively. Increased preschool attendance showed a negative correlation with reduced mortality among children aged $0-4$ years. Among children aged 5-14 years, an increased number of pedestrian crossings showed a strong but insignificant association with reduced mortality rates. The model including the increase in pedestrian crossings explained $5 \%$ of the mortality rate changes among children aged 5-14 years. The other models for this age group did not explain the mortality changes $(0 \%)$.

\section{DISCUSSION}

This study shows that increased numbers of public parks correlate with decreased motor vehicle related mortality rates, a proxy for pedestrian mortality reductions, of children aged 0-4 years but not of those aged 5-14 years. Despite the limitations of ecological studies, such as weak indicators or a lack of indicators of potential confounders, we can support a causal inference of this conclusion by discussing the implausibility of alternative explanations. Potential determinants of reduced child pedestrian mortality rates include reduced vehicle speed, improved trauma care, improved vehicle designs, increased safety facilities, and strengthened law enforcement, ${ }^{11-14}$ 19-23 $^{2}$ all items that were not considered in our models.

Reductions in vehicle speed through traffic calming schemes or urbanisation, ${ }^{12} 141922$ improved vehicle designs, ${ }^{23}$ and improved trauma care ${ }^{21}$ can reduce the severity of injuries and case fatalities, leading to mortality reductions. The effects of these changes should be universally true for all of a population, regardless of age or types of road user. Lowered vehicle speeds would reduce the energy transferred to victims at the time of crashes. Improved vehicle design is favourable both to occupants and non-occupants. ${ }^{23}$ Improved trauma care can reduce mortality of both children and adults. $^{21}$ However, as shown in our results, occupant mortalities did not decline during the study period; pedestrian mortality rates among adults, including adolescents and the elderly, did not change from the mid-1970s to the mid1990s. ${ }^{56}$ Thus, these effects cannot explain the mortality reduction found throughout the study period, although they might have contributed to the reduction seen in the early 1970s.

\section{Key points}

- Child pedestrian mortalities showed a huge decline, which accounted for a larger proportion of the decline in overall motor vehicle related mortality. Other categories of vehicle related mortalities did not show substantial declines during the study period.

- Trends in the numbers of public parks were associated with trends in motor vehicle related mortality rates, which are proxy measures of pedestrian mortality rates, of preschool children.

- Trends in the number of pavements alongside local roads were not associated with trends in vehicle related child mortality rates. This might be because the percentage of local roads with pavements was too low to be effective.
We could not show the effects of increased numbers of safety facilities, such as pavements and pedestrian crossings; although countries separating pedestrian areas from traffic achieve lower child pedestrian injury rates. ${ }^{10}$ However, running out accounted for most of the children associated pedestrian injuries in Japan: being $78 \%$ of preschooler injuries in $1971 .{ }^{24}$ This might be because safety facilities mainly increased along main roads carrying heavy traffic, but along small roads in residential areas, where children are more likely to be injured, ${ }^{15}$ the numbers of new safety facilities remained too low to effectively separate children from traffic.

Likewise, increased law enforcement was not associated with mortality reduction because such practices were focused largely on main roads, or alternatively, because they were strengthened only in areas with higher vehicle related mortalities. Some enforcement activities might not effectively modify traffic environments. A survey in Tokyo indicated that despite reinforced enforcement, illegal kerb parking, a risk factor of child pedestrian injury, ${ }^{11}{ }^{19}$ increased until the mid1980 s, $^{25}$ up until which point vehicle related child mortality rates in Tokyo had decreased constantly.

There are several plausible explanations supporting a causal inference. Firstly, the different results between preschool and school age children found in this study are consistent with child developmental stages. School age children walk longer distances and cross more roads than preschoolers, and are more often injured far from their residential area; preschoolers are mostly injured as pedestrians while playing in their neighbourhood. ${ }^{15}$ In 1985, collisions within 50 metres from the child's residence accounted for $42 \%$ of preschoolers' and $11 \%$ of school age children's pedestrian deaths ${ }^{26}$; and in $2000,40 \%$ and $18 \%$, respectively. ${ }^{1}$ Confining their outdoor activities to safe places would reduce this exposure to risk, and therefore preschoolers might gain better protection from playing in neighbourhood public parks; school age children might gain better protection from pedestrian crossings. Previous studies could have obscured the favourable effects of neighbourhood play areas by including school age and preschool children in one group. ${ }^{11}{ }^{12}$

Secondly, an increased number of neighbourhood parks results in a reduction in the distances travelled to and from them because inhabitable areas in Japan have not dramatically changed throughout the study period. ${ }^{27}$ Distance reduction can lessen the exposure to traffic during the journey to and from such parks, which has been given as an explanation for the lack of associations in previous studies. ${ }^{12}$ Also, shorter distances might encourage parents to accompany their children to the park thus reducing a child's injury risk during these journeys. ${ }^{28} 29$

Thirdly, an increased number of play areas might represent a change in population risks rather than individual risks. In areas where there are more public parks, children are likely to play in them. Risk reduction at an individual level, in this case, might be so small that individual data cannot detect it because pedestrian injury is a rare event. However, a small reduction in individual risks might add up to the significant reduction in gross population risks that an ecological study can identify.

Finally, we believe that increased numbers of public parks represent more comprehensive environmental changes and consequential changes in the behaviours of drivers. Building a new park is usually accompanied by other safety facilities and parking regulations, which might bring about a combined effect. The multicolinearity shown in the multiple regression analysis showed that prefectures with a higher increase in parks also showed a higher increase in other facilities. 


\section{Limitations}

Our models could not include direct measurements of children's reduced outdoor activities, which can considerably contribute to a reduction in child pedestrian mortality by reducing exposure to traffic ${ }^{83031}$; today children in Japan spend more time at home watching television and playing video games. ${ }^{32}$ We could use only proxy measurements of children's exposure by using administrative data: preschool attendance reflects only a part of the exposure changes; exposure to traffic would reduce while in such facilities, but might also increase during the journey to and from the preschool. Nevertheless, this would not have confounded the results, although the contribution of reduced outdoor activities to the mortality reduction could not be estimated. If the reduction of outdoor activities was a confounder, it should also be independently associated with the increase of parks.. ${ }^{33}$ It is, however, unlikely that increased parks lead to children's activity reduction or vice versa as neighbourhood parks would encourage rather than discourage children's outdoor activities or policy response is not so prompt. If newly built parks increased children's outdoor activities, it would be a negative confounder, resulting in an underestimation of the associations. ${ }^{34}$

Furthermore, some other variables were also, by necessity, proxy measurements and contributed to a weak model fit. The number of ambulances does not reflect the total quality of EMS and trauma treatments, and population density cannot fully reflect various aspects of urbanisation. However, these factors may not be plausible explanations of children's mortality reduction as discussed, thus they may not confound the associations; although we could not precisely estimate their effects.

Despite the weak model, statistical significance was obtained and we could suggest that the potential effects of safe play areas for preschoolers in reducing pedestrian deaths. We cannot propose a decisive conclusion because of the limitations of an ecological study. Therefore, to confirm our findings, further research using individual data is needed; investigating the reduction in children's exposure to traffic after the installation of such facilities, and the subsequent reduction in pedestrian mortality and morbidity.

\section{CONTRIBUTORS}

SN was leading researcher; YN and MI were involved in study design, data analysis, interpretation, and writing of the manuscript; and SW was guarantor and contributed to data analysis, interpretation, and final preparation of the manuscript.

\section{Authors' affiliations}

S Nakahara, M Ichikawa, S Wakai, Department of International Community Health, Graduate School of Medicine, The University of Tokyo, Tokyo, Japan

Y Nakamura, Department of Human Scientific Studies of Volunteer Activities, Graduate School of Human Science, Osaka University, Osaka, Japan

Funding: none.

Conflicts of interest: none declared.

\section{REFERENCES}

1 Institute for Traffic Accident Research and Data Analysis. Traffic statistics 2000. Tokyo: The Institute, 2001.

2 The Ministry of Health, Labour and Welfare. Vital statistics 1999. Tokyo: The Ministry, 2001.

3 Tanaka T. Kodomo no jiko boshi manual. [In Japanese]. Tokyo: Shindan to Chiryosha, 1995.

4 Ochi T. Kotsukanri no hensen. [Changes in traffic management]. IATSS Rev 1994;20:4-15.

5 Management and Coordination Agency. White paper on traffic safety 1999. Tokyo: The Agency, 1999.

6 Nakahara S, Nakamura Y, Wongkhomthong S. Trend of traffic injuries to children and prevention measures in Japan. Mahidol J 2000;7:49-52.

7 United Nations Children's Fund. A league table of child deaths by injury in rich nations. Innocenti report card no 2. Florence: UNICEF Innocenti Research Centre, 2001.

8 Roberts I. Why have child pedestrian death rates fallen? BMJ 1993;306:1737-9.

9 Bergman AB, Rivara FP. Sweden's experience in reducing childhood injuries. Pediatrics 1991;88:69-74.

10 Roberts IG. International trends in pedestrian injury mortality. Arch Dis Child 1993;68:190-2.

11 Agran PF, Winn DG, Anderson CL. The role of the physical and traffic environment in child pedestrian injuries. Pediatrics 1996;98:1096-103.

12 Mueller BA, Rivara FP, Lii S, et al. Environmental factors and the risk for childhood pedestrian-motor vehicle collision occurrence. Am J Epidemiol 1990;132:550-60.

13 Stevenson M, Jamrozik K, Burton P. A case-control study of childhood pedestrian injuries in Perth, Western Australia. J Epidemiol Community Health 1996:50:280-7.

14 von Kries R, Kohne C, Bohm O, et al. Road injuries in school age children: relation to environmental factors amenable to interventions. Inj Prev 1998;4:103-5.

15 Saito R. Child traffic accidents in Japan. Acta Paediatr Jpn 1993;35:207-14.

16 Ministry of Public Management, Home Affairs, Posts and Telecommunications. Population census 2000. http://www.stat.go.jp/ english/data/kokusei/index.htm (accessed 7 April 2004).

17 Su S, Shih CL. Modeling an emergency medical services system using computer simulation. Int J Med Inf 2003;72:57-72.

18 Armitage P, Berry G, Matthews JNS. Analysing non-normal data. In: Statistical methods in medical research. 4th ed. Malden, MA: Blackwell, 2002.

19 Roberts I, Norton R, Jackson R, et al. Effect of environmental factors on risk of injury of child pedestrians by motor vehicles: a case-control study. BMJ 1995:310:91-4.

20 Roberts I, Marshall R, Norton R. Child pedestrian mortality and traffic volume in New Zealand. BMJ 1992;305:283.

21 Roberts I, Campbell F, Hollis S, et al. Reducing accident death rates in children and young adults: the contribution of hospital care. BMJ 1996;313:1239-41.

22 Barss P, Smith G, Baker SP, et al. Traffic Injuries. In: Injury prevention: an international perspective. New York: Oxford University Press, 1998:103-50.

23 Robertson LS. Reducing death on the road: the effects of minimum safety standards, publicized crash tests, seat belts, and alcohol. Am J Public Health 1996;86:31-4.

24 National Police Agency. Annual report of traffic accidents 1971. Tokyo: The Agency, 1972.

25 Doro kotsumondai kenkyukai. Doro kotsu seisakushi gaikan. [In Japanese] Tokyo: Pro Com Japan, 2003.

26 National Police Agency. Traffic statistics 1985. Tokyo: The Agency, 1986.

27 Ministry of Public Management, Home Affairs, Posts and Telecommunications. Japan statistical yearbook. Tokyo: The Ministry (annually).

28 Roberts I. Adult accompaniment and the risk of pedestrian injury of the schoolhome journey. Inj Prev 1995;1:242-4.

29 Pless IB, Verreault R, Tenina S. A case-control study of pedestrian and bicyclist injuries in childhood. Am J Public Health 1989;79:995-8.

30 Nakahara S, Wakai S. Differences between Japanese pre-school and school age pedestrian mortality and morbidity trends. Public Health 2002;116:166-72.

31 DiGuiseppi C, Roberts I, Li L. Influence of changing travel patterns on child death rates from injury: trend analysis. BMJ 1997;314:710-13.

32 Yamaguchi T. Change in daily life activities of children at a day care school. [In Japanese]. Shoni hoken kenkyu 1994;53:471-8.

33 Newman TB, Browner WS, Hulley SB. Enhancing causal inference in observational studies. In: Hulley SB, Cummings SR, Browner WS, et al. Designing clinical research. 2nd ed. Philadelphia, PA: Lippincott Williams and Wilkins, 2001:125-41.

34 MacMahon B, Trichopoulos D. Cohort studies. In: Epidemiology: principles and methods. 2nd ed. Boston, MA: Little, Brown, 1996:165-227. 